\title{
MANAGEMENT PLAN FOR CLIMATE RESILIENCE OF COASTAL AREAS IN TOGO
}

\author{
Aurélie Le Dissez, ATELIA, aurelie.ledissez@arteliagroup.com \\ Eric Lagroy de Croutte, ARTELIA, eric.decroutte@arteliagroup.com \\ Luc Hamm, ATELIA, luc.hamm@arteliagroup.com
}

\section{CONTEXT}

Bight of Benin coast is highly vulnerable to climate change and one of its negative effects: sea level rise. It affects the coastal zones of Ghana, Togo and Benin. Within these areas, a substantial impact is expected not only on livelihoods but also on key infrastructure in coastal areas, leading to the destruction of coastal line and its habitats, socio-economic mutations and beach erosion increase. In Togo, the erosion retreat, due to improper coastal and infrastructure management, has been estimated between 5 to 10 meters per year during the period 1955-1985 and 20 to 30 meters per year during the period 1985-2009, forcing the coastal road linking Lomé to Aného to be moved twice. Taking into consideration climate change, this figure will progressively increase.

Under the African Development Fund 13th cycle (2014 2017), the African Development Bank (AfDB) is supporting the Togolese government's effort of strengthening regional integration through the financing of transport infrastructure, in particular the "rehabilitation of the corridor Lome-Cotonou and transport facilitation project". The main objective of AfDB project is to finance the related infrastructure and capacity building that will make coastal infrastructure, roads in particular, climate resilient.

\section{OBJECTIVES}

In the frame of this global project, ARTELIA has been mandated by the AfDB to study an integrated coastal zone management plan which aims at protecting the 15 $\mathrm{km}$ shoreline located between Baguida (Western extremity of the study area) and Kossi Agbavi (Eastern one). The project focused specifically on:

1) making infrastructure climate resilient and therefore mitigate the risk of seeing human assets and transport infrastructure harmed or destroyed by coastal erosion, 2) supporting local coastal communities, who exploit the coastal sand and marine gravel, in their professional reconversion, since this banned but lucrative Income Generating Activity enhances the current erosion issue and has to be stopped. Therefore, the project has to promote strategies and activities to diversify and strengthen communities' livelihood in order to increase the adaptive capacity of communities in the area in front of the effect of climate change on the coastal line (sea level rise and sand scarcity).

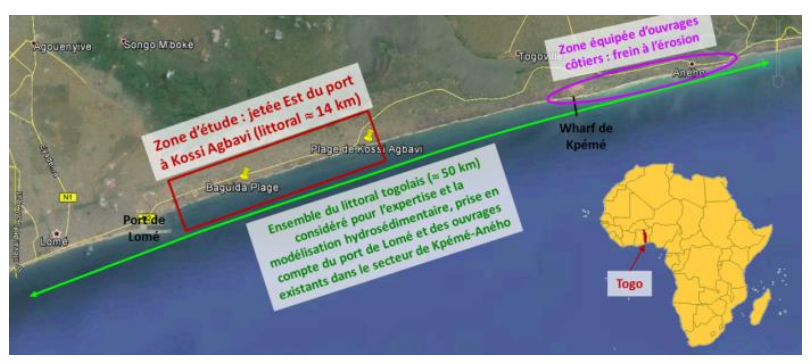

Figure 1 - Location of the area study

\section{STUDY METHODOLOGY}

To achieve such goals, ARTELIA implemented an integrated methodology, including economic, financial and socio-environmental risk assessments, all depending on the findings of the hydro-sedimentary central study. The paper will present the different components of the study and their linkage, and will particularly focus on the hydro-sedimentary one, comprising the analysis of Togolese coastal environment profile in current situation (though bibliography, community consultation / data collection on field....), the evaluation of sea level rise due to climate change in Togo, the analysis of the past and recent shoreline evolutions, related to history of human interventions to provide calibration data to a modelling of the shoreline evolution (using UNIBEST software).

Once calibrated, this model has been used to test different solutions of shoreline protections (hard structures/combination of hard and soft structures), and to predict, under each tested configuration, the future shoreline position in mid and long terms taking into account the sea level rise for the longer term horizon.

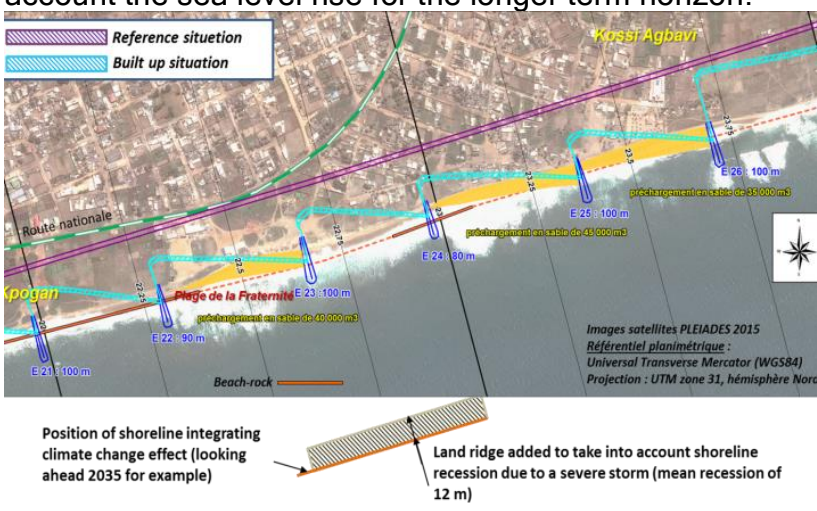

Figure 2 - Expected shoreline position in 20 years, in reference situation and in built up situation

\section{INTEGRATED COASTAL ZONE MANAGEMENT}

Thanks to a multi-criteria analysis comparing costs of construction of the different solutions and their expected profit in terms of mitigation of land and economical losses, a coastal management plan was proposed. It will be detailed in this paper as well as accompanying recommendations in terms of Knowledge Management, Monitoring and Evaluation program, and development of an Early Warning System.

\section{REFERENCES}

FEM-UNDP, Ministry of Environment and Forestry (2010): Second national communication of Togo on Climate Changes.

FAO (2014): Reconversion options for actors involved in marine sand extraction in Togo.

\section{ACKNOWLEDGEMENTS}

ARTELIA wishes to acknowledge with thanks the contribution of the AfDB and Togolese Ministry of the Environment and Forestry Resources 